УДК 340.11

DOI https://doi.org/10.17308/vsu.proc.law.2020.3/3002

\title{
НРАВСТВЕННОСТЬ - БАЗИС И ВЫСШАЯ ЦЕННОСТЬ ДЛЯ ПРАВОВОГО РЕГУЛИРОВАНИЯ И ФОРМИРОВАНИЯ МЕХАНИЗМА ПРАВООТНОШЕНИЙ
}

(Рец. на кн.: Серков П. П. Правоотношение (Нравственность современного правового регулирования) : монография / П. П. Серков. -

$$
\text { М. : Норма, 2020. }-688 \text { с.) }
$$

\section{Ю. Н. Старилов}

Воронежский государственный университет

Поступила в редакцию 20 июля 2020 г.

\begin{abstract}
Аннотация: оцениваются суждения П. П. Серкова о нравственности как идейной основе механизма правоотношений, на которой возможно максимальное сближение науки и практики с иелью объединения их усилий для стимулирования надлежащего субъективного поведения. Автор монографбии, основываясь на своем критическом взгляде на распространенные в юридической науке традиции, представления и фундалентальнье подходы, обосновывает оригинальнье идеи, показывающие великий потенциал нравственной составляющей механизла правоотношений. Используемая в исследовании методология механизма правоотношений способна определять их нравственную сущность, благоприятно воздействовать на юридическую практику, учитывать сложности, проблемы и недостатки юридического пространства и, как следствие, создавать надлежащие модели правовой реальности. Ознаколление с монографбией позволит читателю более акцентированно и широко взглянуть на роль нравственньх оснований и лоральных иенностей в деле создания и развертывания систель совреленного правового регулирования. Делается вывод, что монографбия П. П. Серкова вносит весьла крупный вклад в развитие теории правоотношений.

Ключевые слова: механизл правоотношений, правовое регулирование, нравственность, мораль, право, нравственные паралетры конституицонно-правовой регламентаиии, правосознание, правопонимание, нравственные начала юридической науки.
\end{abstract}

Abstract: Evaluated the judgments of P. P. Serkov about morality as the ideological basis of the mechanism of legal relations that maximally bring together science and practice in order to combine their efforts to stimulate appropriate subjective behavior. The author of the monograph, based on his critical view of the traditions, ideas and fundamental approaches widespread in legal science, substantiates original ideas showing the great potential of the moral component of the mechanism of legal relations. The methodology of the mechanism of legal relations used in the study is capable of determining their moral essence, positively influencing legal practice, taking into account the difficulties, problems and shortcomings of the legal space and, as a consequence, creating appropriate models of legal reality. Acquaintance with the monograph allow the reader to

(C) Старилов Ю. Н., 2020 


\section{Вестник ВГУ. Серия: Право}

take a more focused and broad look at the role of moral foundations and moral values in the creation and deployment of a system of modern legal regulation. It is concluded that the monograph by $P$. P. Serkov makes a very large contribution to the development of the theory of legal relations.

Key words: mechanism of legal relations, legal regulation, moral, morality, right, moral parameters of constitutional and legal regulation, legal awareness, legal thinking, moral principles of legal science.

Монография «Правоотношение (Нравственность современного правового регулирования), написанная П. П. Серковым - автором крупных научных трудов, в том числе и произведения «Правоотношение (теория и практика современного правового регулирования)» ${ }^{1}$, заставляет сразу же задуматься над традиционными вопросами соотношения и взаимодействия права и морали, нравственных качеств и правовых воззрений, нравственных регуляторов и системы правового регулирования. Сколько по времени существует философия и юридическая наука, столько и по-разному, но одновременно эмоционально и содержательно ученые пишут об этих важнейших регуляторах общественных отношений. Очевидно, что теория указанных проблем со временем упростилась: на протяжении многих десятилетий анализируются лишь доминирующие параметры их соотношения и взаимовлияния. Вряд ли следует гадать о том, что весьма объемный научный труд П. П. Серкова о теории правоотношения (2019 г.), возможно, по замыслу автора, сознательно им не был завершен. Поэтому следом и появилась новая монография, посвященная исследованию проблем «нравственности правового регулирования» (ведь именно такое словосочетание взято автором за основу проведенного системного анализа правоотношения). Сам автор во введении к книге говорит, что «целесообразно продолжать выявление конкретики действия механизма правоотношений, теперь в контексте нравственности» ${ }^{2}$. Несомненно, авторское предположение верно и в том, что данные параметры исследования создадут основу как для систематизации накопленного опыта исследования механизма правоотношений, так и для реализации новых возможностей для развития указанного направления в обозримой перспективе ${ }^{3}$. Используемая методология механизма правоотношений способна акцентированно определять их нравственную сущность, благоприятно воздействовать на порождаемую юридическую практику, учитывать сложности, проблемы и недостатки и, как следствие, создавать надлежащие модели правовой реальности. Весь исследовательский потенциал механизма правоотношений, по заверениям П. П. Серкова, содействует разумному познанию «закономерностей правового регулирования» (с. 541). Рецензируемый научный труд стал итогом междисцип-

${ }^{1}$ См.: Серков П. П. Правоотношение (теория и практика современного правового регулирования) : монография : в 3 ч. М. : Норма, 2019.

${ }^{2}$ Серков П. П. Правоотношение (Нравственность современного правового регулирования) : монография. М. : Норма, 2020. С. 34.

${ }^{3}$ См.: Там же. 


\section{Рецензии}

линарного целенаправленного поиска ответов на поставленные перед автором вопросы.

Монография, как и предыдущая работа П. П. Серкова, написана сложным языком; в логическую связь переплетены весьма громоздкие предложения, теоретические конструкции, критические суждения, включающие как соответствующие аргументации противоречивости анализируемых взглядов, так и обоснование собственных подходов к развитию новых идей. Право, мораль, фрилософия, история, юридическая наука, прошлое и современность, итоги и перспективы будущего - все это вошло в предмет исследуемой темы, а именно механизма правоотношений в конкретике взаимоотношений с опосредованием с нравственностью. Текст книги сложный, но и одновременно понятный, с ясными задумками теоретического описания и взорами в нарождающиеся новые механизмы правового регулирования, появление которых, как можно предположить, и является одной из главнейших задач юридической науки, заключающейся в разработке «концепции социального благополучия с учетом исследований других наук» (с. 646). В таком целеполагании, думается, можно обнаружить сходство воззрений П. П. Серкова с известным правовой истории поиском новых движений в юриспруденции, куда «с самого начала старались привлекать профессоров, «умевших соединять историю, философию и литературу с непосредственно примененными науками». Из этого соединения и должно было вырасти новое научное направление в юриспруденции» ${ }^{4}$. В этом смысле призыв П. П. Серкова, выраженный, по сути, в каждом параграфе монографии своими средствами и утверждениями, может стать опорным пунктом для создания новейшего направления юридической науки, базирующейся на нравственных началах и прогнозирующей нравственные перспективы (с. 612-686). В сущности, монография П. П. Серкова в какой-то степени продолжает вековой спор юристов исторической школы права и естественного права, которые во все времена искали «систему норм, одинаково пригодных для всех времен и народов»; при этом естественное право представлялось как «совокупность идеальных (нравственных) представлений о праве», которые в сущности носили нравственный характер и считались проявлением «высшего нравственного порядка» ${ }^{5}$. Очевидно, идейная направленность теоретических положений П. П. Серкова с упором на механизм правоотношений и роли нравственности в современном правовом регулировании может соперничать и с англосаксонской доктриной верховенства права и романо-германской доктриной правового государства, каждая из которых по-своему объясняет роль права в жизни человека, общества и государства. Можно предположить, что изложенная в монографии П. П. Серкова «нравственная нормативность» стала бы известным компромиссом происходящей конвергенции указанных правовых доктрин.

${ }^{4}$ Новгородиев П. И. Историческая школа юристов. Ее происхождение и судьба // Немецкая историческая школа права. Челябинск : Социум, 2010. С. 32.

${ }^{5}$ Там же. С. 6-8. 


\section{Вестник ВГУ. Серия: Право}

Создавая теорию механизма правоотношений и правового регулирования, П. П. Серков в начало всех дискуссий ставит выявление вопросов нравственных критериев нормотворчества, а также ценности нравственных проявлений и идеалов правового воздействия на субъектов общественных отношений и межличностного взаимодействия. Механизм правоотношений, основанный на силе идейного содержания нравственного потенциала в процессе создания правовых норм, неизбежно приведет к очевидному улучшению социальной жизни посредством гарантирования взаимности и паритетности субъективных прав и обязанностей, «оптимизации правового регулирования межличностного общения» (с. 541).

Вдумчивое изучение сложно написанных научных трудов - вопрос непростой. Нужна известная подготовка, опыт исследовательской работы, собственная методика поиска ответов на вопросы, возникающие в процессе прочтения. Понимание сложности обсуждаемой в работе проблемы и способов ее решения формируется не сразу. Обычно это происходит так: вначале читатель просто перелистывает новую книгу, а затем с большим усердием и вниманием вникает в суть написанного. При этом сложившиеся убеждения и научные представления вначале доминируют при сопоставлении предлагаемых теоретических суждений, новых подходов к решению обозначенных задач. В данном случае П. П. Серков на каждой странице книге выделяет достаточно много слов или словосочетаний полужирным шрифтом и одновременно делает их курсивол, как бы «помогая» читателю определиться с главными терминами, важнейшими формулировками, центральными понятиями, вкладываемым в них смыслом и толкованием. С одной стороны, такие рекомендации автора действительно дают возможность сразу же обращать на них внимание и системно анализировать. С другой стороны, это в определенной мере предопределяет общие подходы и к анализу текста, и формулируемым первичным выводам. Правда, нужно отметить, что указанная методика представляет собой оригинальный подход автора, его собственный стиль, присущий всем научным трудам П. П. Серкова.

Таким образом, правовое регулирование просматривается и исследуется автором под воздействием нравственных принципов. В связи с этим рождаются вопросы: в чем сила нравственности? Какое она оказывает воздействие как на процесс правообразования, так и сам механизм правового регулирования? Когда можно говорить, что нравственность воплощена в праве и правовом регулировании? Или, возможно, лучше признать их обособленность друг от друга, а их одновременное действие на социальную и государственную жизнь с различных сторон, с целью решения конкретных задач считать приоритетным решением вопроса об их взаимоотношениях? В начале книги ставится, с моей точки зрения, главный вопрос: о необходимости «разобраться... что непосредственно в самом человеке усложняет правовое регулирование, а что повышает его эфрфективность» ${ }^{6}$.

\footnotetext{
${ }^{6}$ Новгородиев П. И. Указ. соч. С. 6-8.
} 


\section{Рецензии}

Через весь текст монографии заметно проводится авторская мысль о методологии, основанной на "взаимности и паритетности прав и обязанностей», позволяющей юридической науке стать «реальным помощником обществу и государству в организации благополучной жизни каждого человека» (с. 647-648). Логика обоснования автором механизма правоотношений распространяется здесь и на организацию правового регулирования, поставив последнее под власть нравственной атмосферы и ее превалирующего влияния на порядок нормотворчества и применения юридических норм. Эти идеальные представления порождены верой автора в могущество нравственных начал в правовом регулировании общественных отношений, результатом которых и должны стать гарантии реального (т. е. на практике, в действительности) равенства, свободы, справедливости, правильности, обоснованности, добросовестности, паритетности, взаимности, пропорциональности, правового баланса. Как часто практические задачи юридической науки и правотворчества, их многообразие и сложность закрывают дорогу прогрессивному применению полезных для общества и государства моральных ценностей и нравственных постулатов и поэтому препятствуют развитию общих социальных регуляторов и их рационального внедрения в правовую среду, в механизм правового регулирования. Как правило, объяснением этого становятся сиюминутные интересы, возникшие проблемы, необходимость скорейшего урегулирования противоречий.

Очень важно понимать, что соотношение нравственности и права и степени их взаимопроникновения, как бы это не казалось второстепенным, анализируется в разные исторические эпохи по-разному. Сама нравственность рассматривается (в том числе и применительно к государственной деятельности, законотворческой деятельности, формам и методам работы государственного аппарата, государственных служащих) часто по-разному. Думается, что П. П. Серков призывает распространять вечные, не подлежащие корректировке в разные исторические эпохи, «высокие» нравственные критерии на правила правообразования, механизм правоотношений, юридическую практику, поведение человека. Понятно, что в иные времена действовали разные законы, порой не имеющие к праву никакого отношения. А перестали ли от этого нравственные устои быть определяющими ориентирами в поведении людей, их действиях и решениях? Именно в этом ракурсе неизменность нравственных критериев и должна целиком следить за процессом правообразования вообще и законотворчества в частности. Нравственность способна очистить правовое регулирование от чуждых праву временно устанавливаемых приоритетов и принципов. Здесь позволительно привести несколько ленинских цитат. В 1920 г. В. И. Ленин задал вопрос: «В каком смысле отрицаем мы мораль, отрицаем нравственность?», на который ответил: «В том смысле, в каком проповедовала ее буржуазия, которая выводила эту нравственность из велений бога... Всякую такую нравственность, взятую из внечеловеческого, внеклассового понятия, мы 


\section{Вестник ВГУ. Серия: Право}

отрицаем... Мы говорим, что наша нравственность подчинена вполне интересам классовой борьбы пролетариата» ${ }^{7}$; «мы в вечную нравственность не верим и обман всяких сказок о нравственности разоблачаем. Нравственность служит для того, чтобы человеческому обществу подняться выше, избавиться от эксплуатации труда ${ }^{8}$. Таким образом, нравственность легко подстраивалась под политические задачи развития человека, общества, государства, правовой системы. И таких «приспособленческих» агитаций относительно нравственных ценностей история знает в большом количестве. Следовательно, процесс создания права в таких условиях включает в себя и обусловленные эпохально-историческим развитием «нравственные основы». Бескомпромиссно можно утверждать, что сегодня нет никаких оснований для того, чтобы разделять подобные суждения и соглашаться с ними. С моей точки зрения, одна из завершающих частей книги П. П. Серкова, посвященная анализу нравственных перспектив юридической науки, позволяет разобраться в этих сложных вопросах. Автор убежден, что «механизм правоотношений выступает идейной основой, передающей приходящим поколениям системные способы нравственного достижения конкретики справедливости и добра, а значит, уменьшения безнравственности в форме конкретики несправедливости и зла... Опосредуя каждый акт правового регулирования, механизм правоотношений глобально связует прошлое, настоящее и будущее» (c. 654). П. П. Серков предвидит новое развитие как морали человека, так и нравственного мировоззрения социума, широкого межличностного общения (с. 664); и вряд ли, по его мнению, юридическая наука и научное сообщество должны оставаться в стороне от «нравственного служения», проявляющегося в установлении и следовании высоким смыслам добра, должного и справедливого (с. 663).

Еще один пример и цитата. Ф. Энгельс писал, что «невозможно рас-

으 суждать о морали и праве, не касаясь вопроса о так называемой свободе воли, о вменяемости человека, об отношении между необходимостью и свободой» ${ }^{9}$. П. П. Серков, привлекая внимание читателей к этому ракурсу обсуждаемой проблемы и указывая на подчиненное положение правового регулирования "происходящим социальным процессам», подчер-

328 кивает контексты «создания, воли и свободы» как обязательной триады для каждого человека, и идею необходимости регулирования поведения «свободных людей, наделенных созданием и волей» ${ }^{10}$. Известны также слова В. И. Ленина о законности: «законность должна быть одна, и основным злом во всей нашей жизни и во всей нашей некультурности являет-

${ }^{7}$ Ленин В. И. Задачи союзов молодежи // В. И. Ленин о государстве и праве. М. : Госюриздат, 1958. Т. 2. С. 645.

${ }^{8}$ Там же. С. 648.

9 Энгельс Ф. Анти-Дюринг. Переворот в науке, произведенный господином Евгением Дюрингом. М. : Политиздат, 1988. С. 111.

${ }^{10}$ Серков П. П. Правоотношение (Нравственность современного правового регулирования). С. 35. 


\section{Рецензии}

ся попустительство исконно-русского взгляда и привычки полудикарей, желающих сохранить законность калужскую в отличие от законности казанской» ${ }^{11}$. Оказывается, на режим законности как на результат конкретного правового регулирования в полную силу могут влиять, например, историческая обстановка, условия «классовой борьбы», желание осуществить идею об «отмирании государства», общественное безразличие, требования правовой государственности, уровень и качество правосознания, правовая культура, неизменяемые конституционные ценности и пр. И ведь на всех этапах действия созданного механизма правового регулирования учитывается нравственность и ее приоритеты. А на деле формируются абсолютно разные правовые режимы, формы правления, стили публичного управления, судебная практика. Так, в середине прошлого века А. Я. Вышинский с опорой на труды и взгляды основоположников марксизма-ленинизма по-своему объяснял, например, сущность внутреннего судейского убеждения, принципы правосознания, справедливости, нравственности, "нравственной уверенности», «нравственном начале», «свободном усмотрении» ${ }^{12}$, находя в трудах ученых «эклектику» и «упрощенчество», приходил к выводу об очевидности "роли господствующих в данном обществе нравственных принципов» и «общественных идей в данном случае» ${ }^{13}$. Здесь вполне уместно вспомнить суждения С. С. Алексеева по вопросам единства морали и права, констатирующего устойчивое утверждение о том, что «право должно отвечать требованиям морали. Но далеко не всем и не всяким и тем более - не идеологизированным (таким как требования средневековой инквизиции, расового превосходства, «коммунистической морали»), не неким идеологизированно «высшим»таким как Спасение, Освобождение от зла, Всеобщее счастье, иным, порой мессианского порядка» ${ }^{14}$. Нравственность современного правового регулирования, по П. П. Серкову, успешно сочетается с осторожностью С. С. Алексеева, развивавшего сомнение в обоснованности «нацеленности права на воплощение в жизнь высоких нравственных начал и идеалов» ${ }^{15}$. Безусловно, невозможно переоценить значение и предназначение нравственных устоев для организации социальной жизни, осуществления правового статуса человека. Юридические понятия, правила, процедуры, порядки, нормы, институты - все они порой ясно, но иногда и в трудно различаемых пределах включают нравственные ориентиры, требования, факторы обеспечения морального режима. И это нужно считать главным, даже если для реализации механизма правового регулирования станут востребованными в допускаемых государством пределах

${ }^{11}$ Ленин В. И. О «двойном» подчинении и законности» // В. И. Ленин о государстве и праве. М., 1958. Т. 2. С. 721.

${ }^{12}$ См.: Вышинский А. Я. Теория судебных доказательств в советском праве. Изд. третье, доп. М.: Гос. издательство юридической литературы, 1950. С. 148.

${ }^{13}$ Там же. С. 215.

${ }^{14}$ Алексеев С. С. Восхождение к праву. Поиски и решения. М. : НОРМА, 2001. C. 207.

15 Там же. С. 215. 


\section{Вестник ВГУ. Серия: Право}

законности меры административного властвования, государственного принуждения, применения установленных в законах принудительных правовых средств. Если попытаться выйти из невероятно запутанных в истории права и государства взаимодействий базовых моральных ориентиров в построении правовой системы и механизма юридического влияния на общество, то появляется желание воздвигнуть на пьедестал истинные, доминирующие во все время нравственные стимулы, направленные на создание. Можно предположить, что суждения П. П. Серкова, конкретизирующие действие механизма правового регулирования с учетом потенциала нравственности и его воздействия на формируемые правоотношения, позволяют увидеть так называемые модельные сущностные черты и принципы влияния неизменных нравственных регуляторов как на правовое регулирование, так и на правоприменение.

Чтобы оценить авторские подходы к анализу нравственности и ее влияния на правовое регулирование, на учет, очевидно, разнообразнейших и весьма востребованных современным человеком, законодателем и всеми субъектами права критериев, оценок, внутренних убеждений, нужно вначале вспомнить традиционные подходы к выявлению сочетания права и морали. И здесь П. П. Серков глубоко, широко и всесторонне рассматривает данные вопросы соотношения морали и нравственности, морали и права ${ }^{16}$; попутно критически относится к высказываниям и теоретическим конструкциям ученых, исследующих, как полагает он, данные вопросы в несистемном виде, связанном «с неопределенным пониманием права" и оторванном именно от "правового регулирования» ${ }^{17}$. По мнению автора, вряд ли допустимо простое совпадение нравственности с правом; в противном случае, как пишет П. П. Серков, «нравственные запреты станут юридическими» и, таким образом, исчезнут «различия между правом и нравственностью» ${ }^{18}$.

Прочтение монографии П. П. Серкова «Правоотношение (Нравственность современного правового регулирования)» «принуждает» читателей к пересмотру либо более внимательному изучению теории правового регулирования, которая в своей сущности является в отечественной юридической науке весьма понятной, ясной и малопротиворечивой на протяжении многих десятилетий. Однако из названия рецензируемой книги становится очевидным главный замысел автора - посмотреть на содержание механизма (системы) правового регулирования как-то по-другому, с выявлением акцентированного воздействия на этот важнейший инструмент правообразования нравственности, моральных ценностей, правовых чувств. Как видно, автору хотелось бы, чтобы весь процесс правового регулирования и вся его структура просматривались и основывались преимущественно на сущности высоких нравственных подхо-

${ }^{16}$ См.: Серков П. П. Правоотношение (Нравственность современного правового регулирования). С. 44-69.

17 Там же. С. 46.

${ }_{18}$ Там же. С. 50. 


\section{Рецензии}

дов к осуществлению правотворческой деятельности. Именно поэтому П. П. Серков большую часть исследования проводит в главе, которая называется «Нравственность конституционно-правового регулирования» (c. 215-389). Однако и в этой сфрере рождаются новые идеи, которые обосновываются учеными сегодня. Например, Н. С. Бондарь сформулировал некоторые положения, касающиеся понимания и развития конституционных идеалов. При этом установил и обосновал «глобальный дефицит конституционного равенства», «деформацию социокультурных начал в праве», «отрыв системы нормативно-правового регулирования от нравственно-этических основ» ${ }^{19}$. Духовные начала Конституции Российской Федерации, нравственно-этические начала права в новую эпоху развития конституционализма и в связи с глобальными изменениями экономических отношений, невероятно стремительным развитием цифровых технологий, а вместе с ними и цифрового права, «цифрового» общества и государства поставили в повестку дня вопрос о нравственности правового регулирования на совершенно новый уровень. Именно в этом контексте также востребованы рассуждения П. П. Серкова, детализирующие вопросы понимания механизма правоотношения с позиций его взаимодействия с нравственностью.

Анализируя объемный научный труд П. П. Серкова, уместно вспомнить известную публичную лекцию Г. Ф. Шершеневича «О чувстве законности» ${ }^{20}$, прочитанной более 120 лет назад, но ничуть не потерявшей своей актуальности и значимости в наши времена. Наоборот, главные идеи Г. Ф. Шершеневича настраивают как законодателей, так и правоприменителей на развитии адекватной современным представлениям о праве, правовой системе, государстве и государственной деятельности профессиональной активности созидателей правовых образов, терминологий, юридических норм и институтов. Г. Ф. Шершеневич писал, что «прежде чем говорить о законности, нам необходимо условиться относительно того, что мы будем понимать под правом, которого видом является закон. Право есть норма, т. е. общее правило, определяющее поведение человека в отношении других людей, составляющих с ним вместе политическое единство, государство. Однако эта задача выполняется не одними юридическими правилами, но и иными нормами, ближе всего нормами нравственности» ${ }^{21}$.

Следовательно, прежде чем говорить о правовом регулировании вообще, нам следует впереди рутинной законотворческой деятельности поставить нравственные нормы и их великий созидательно-контролирующий потенциал, воздействующий на формирование самих правоотношений. Именно в этом смысле нравственные основания осуществления деятель-

${ }^{19}$ См.: Бондарь Н. С. «Вечные» конституционные идеалы : насколько они неизменны в меняющемся мире? // Государство и право. 2020. № 6. С. 27-28.

${ }^{20}$ См.: Шершеневич Г. Ф. О чувстве законности // Шершеневич Г. Ф. Избранное / вступ. слово, сост.: П. В. Крашенинников. М. : Статут, 2016. С. 449-471.

${ }^{21}$ Там же. С. 449. 


\section{Вестник ВГУ. Серия: Право}

ности по развитию системы правового регулирования дают возможность разглядеть в итоге желание общества к соблюдению установленных правопорядков, правил, ограничений, запретов и иных воздействующих на субъектов права требований. «Побуждение соблюдать установленные законы ... не сообразуясь с конкретными условиями их применения» и есть чувство законности, по Г. Ф. Шершеневичу ${ }^{22}$. Возникшее из нравственных обоснований качество юридического воздействия на общество и государство правовое регулирование напрямую активирует чувства, способные создать иные представления о желаемых, идеальных конструкциях правового воздействия. Для П. П. Серкова чувства, эмоции и мотивы как формы переживания юридических событий и практики, как ценностные грани механизма правоотношений представляют собой «фундамент законности и надлежащего правопорядка» (с. 485). П. П. Серков, отрицая идейную безысходность в пространственном развитии правового регулирования, призывает включать в него нравственность и его высокие стандарты; именно поэтому автор надеется на то, что нравственность как идейная основа механизма правоотношений «максимально сблизит науку и практику, объединит их усилия», а также способна заметно стимулировать желаемое «надлежащее субъективное поведение» ${ }^{23}$. Нравственное пространство, по П. П. Серкову, должно быть шире, значительнее, первичнее по сравнению с пространством юридическим, несомненно, играющем заметную роль в закреплении правовых статусов самых разных по видам и объему правовых возможностей участников правоотношений.

Нравственность правового регулирования способна гарантированно прививать людям чувство приверженности к устанавливаемым правопорядкам, поддержки правовых принципов, понимания самой многообразной юридической деятельности, приводимой к желаемым взаимодействиям общества и государства, развитию личности и формированию современной правовой культуры. В этом смысле становится непонятным авторское утверждение, что «нравственность лишь по внешнему восприятию может показаться хрупкой субстанцией, а ее потенциал ограниченным» ${ }^{24}$. Ведь концептуальный замысел П. П. Серкова, решаемые в книге задачи, используемые методы исследования и его результаты демонстрируют отнюдь не хрупкость нравственного воздействия на субъектов, осуществляющих деятельность по нормотворчеству. И уж тем более ученый весьма плодотворно раскрывает и показывает созидающий потенциал нравственного воздействия на правовое регулирование многообразных и сложно структурированных общих и отраслевых институтов.

С чем трудно согласиться, так это с утверждением П. П. Серкова о том, что «время общих научных рассуждений о праве безвозвратно уходит» (c. 369). При этом автор целенаправленно выделил в тексте полужирным

${ }^{22}$ Шершеневич Г. Ф. Указ. соч. С. 454.

${ }^{23}$ Серков П. П. Правоотношение (Нравственность современного правового регулирования). С. 389.

${ }^{24}$ Там же. 


\section{Рецензии}

шрифртом слова «уходит» и «безвозвратно». Думается, исследовательский ракурс, выделенный П. П. Серковым в монографии, многозначительно и достоверно доказывает обратное, а именно: понимание современного правового регулирования невозможно развивать и распространять без глубоких дискуссий о предназначении права, насыщения его содержания нравственным смыслом, включения моральных ценностей в сложные и весьма значимые для практики нормотворческие конструкции и процессуальные правопорядки.

Всякие нравственные чувства и характеристика создания человека становятся очевидными независимо от правового регулирования, ибо они сами по себе являются общими регуляторами поведения людей. Но социальная жизнь приобретает новый уровень качества правоприменения в случае, если и система правового регулирования основывается на нравственных потребностях и принципах. Например, совесть; ведь нераскрывшийся потенциал совести или отсутствие внимания к ее состоянию, способного изменять мир права и юридической деятельности, невозможно не заметить на любом этапе правореализации. Лучше, чем М. Е. Салтыков-Щедрин, об этом не скажешь: «Пропала совесть. По-старому толпились люди на улицах и в театрах; по-старому они то догоняли, то перегоняли друг друга; по-старому суетились и ловили на лету куски, и никто не догадывался, что чего-то вдруг стало недоставать и что в общем жизненном оркестре перестала играть какая-то дудка. Многие начали даже чувствовать себя бодрее и свободнее. Легче сделался ход человека: ловчее стало подставлять ближнему ногу, удобнее льстить, пресмыкаться, обманывать, наушничать и клеветать. Всякую болесть вдруг как рукой сняло; люди не шли, а как будто неслись; ничто не огорчало их, ничто не заставляло задуматься; и настоящее, и будущее - все, казалось, так и отдавалось им в руки, - им, счастливцам, не заметившим о пропаже совести. Совесть пропала вдруг... почти мгновенно! ... Исчезли досадные призраки, а вместе с ними улеглась и та нравственная смута, которую приводила за собой обличительница-совесть. ... Люди остервенились; пошли грабежи и разбои, началось вообще разорение» ${ }^{25}$. Именно «нравственная смута» и формирует богатый юридический мир, проверяет его на соответствие правовых замыслов, дел и практики невидимому и одновременно очевидному стандарту множества лучших человеческих качеств. Нравственность есть крайний предел, за которым начинается неблаговидная практика и лишенное силы юридическое пространство. Нравственность - основа созидательного процесса правового регулирования; наконец, нравственность - естественная преграда для проникновения в правовую среду недобросовестности, злоупотреблений, разрушительных диспропорций, несоразмерности, пренебрежения к самим правовым принципам и внушительным правовым ценностям.

В монографии находим весьма интересные мысли П. П. Серкова о совести и ее значении в правовом регулировании, ведь ценность сове-

${ }^{25}$ Салтыков-Щедрин M. E. Сказки. М. : Пан пресс, 2008. С. 15. 
сти - величина неизменная, т. е. всегда высока и должна быть востребована. Автор называет совесть «продуктом морали», так как она «объективно предназначена для нравственного сопровождения каждого акта межличностного общения, независимо от его сугубо социальной или юридической направленности»; сами ощущения совести, по П. П. Серкову, глубинно пронизывают идейное содержание как конституционных, так и иных правовых норм (с. 484-485). Однако «безнравственные события реальной правовой действительности показывают, что существует диапазон бессовестности», что само по себе не означает «переоценки категории совести на уровне конституционного регулирования» (с. 485).

Показывая неразрывные связи нравственности и добросовестности и их сравнимую по силе воздействия межотраслевую значимость (с. 370), П. П. Серков пытается убедить читателя в необходимости известного покрытия самой добросовестности нравственными идеалами, моральными принципами и правовой культурой. Как можно понять из рассуждений ученого, нравственность невозможно отстранить «от правового регулирования, сужая представления о сути добросовестности и предположительно о правовой действительности в целом» (с. 371). Рассматривая отраслевые правовые вопросы, связанные с темой монографии, автор внимательно изучает специальные научные труды, касающиеся, например, формирования и действия административно-правовых норм как культурного феномена (с. 371-372). И здесь отмечается необходимость понимания нравственности как «неотъемлемого атрибута аналитики правового регулирования» (с. 372). Призыв ученого об уяснении глубинных смыслов соотношения нравственности и правового регулирования, очевидно, способен обеспечивать должный порядок во взаимоотношениях субъектов права, обладающих объемными и властно-насыщенными полномочиями в соответствии с действующим административным законодательством, с одной стороны, и лиц, от которых требуется известное подчинение и исполнение правил поведения - с другой. Правовая культура указанных субъектов административных правоотношений, несомненно, будет корректировать качество их взаимоотношений; однако нравственные критерии, положенные в основу нормотворческой деятельности в области административного права, а также распространяющиеся на применяемые административные процедуры, способны создавать бесконфликтную и разумную административную среду.

Анализ новых подходов П. П. Серкова к выявлению взаимосвязи механизма правового регулирования и нравственности нужно проводить на основе созданной им ранее теории правоотношения; при этом не игнорировать при проведении исследования традиционных в теме вопросов о понимании правоотношения, выделении его признаков, выявлении субъектов правоотношения и особенностей объектов правоотношений, субъективных юридических прав и обязанностей, юридических фрактов, фактического состава и классификации правоотношений.

Книга П. П. Серкова о нравственных опосредованиях правового регулирования, очевидно, как получит крайне позитивные отклики и оценки 
научного сообщества, так и вызовет относительно сдержанный скепсис отдельных ученых. Завершающие суждения П. П. Серкова по разработанным им главным положениям о роли морали в формировании современного механизма правового регулирования и его критический подход к распространенным в юридической науке традициям, представлениям и общим подходам, безусловно, будет способствовать развитию фрундаментальных основ нравственной составляющей механизма правоотношений. Можно уверенно предположить, что монография П. П. Серкова внесла заметный вклад в развитие теории правоотношений. Ознакомление с очередной книгой П. П. Серкова позволит читателям более акцентированно взглянуть на роль нравственных оснований и моральных ценностей в деле создания и развертывания системы современного правового регулирования. Терминологическая сложность для подготовленного читателя не станет преткновением, способным уменьшить желание вчитываться в текст книги, познавать ход рассуждений, системно понимать авторский замысел и содержание самого научного труда. Всё становится ясно, если внимательно прочитать последний абзац рецензируемой книги. П. П. Серков в ходе исследования планомерно раскрывал смысл и закономерности идейного содержания правовых норм; поиск сущности, причин возникновения и многообразного развития механизма правоотношений привел исследователя к необходимости познания "сущности человека и социальной организации межличностного общения» (с. 686).

Книга П. П. Серкова способна откорректировать юридическое мышление, включая в него преимущественно нравственные ценности, изменяющие парадигмы самого правопонимания. Авторский напор на отслеживание приоритетных регуляторов поведения современного человека приводит не только к выдвижению нравственности в центр юридической деятельности, но и включению ее идейных свойств во все структуры механизма правообразования и правоотношений. Авторские доводы предоставляют возможность для понимания многих моральных регуляторов, психологических подходов, нравственных ориентиров в обеспечении современного правового регулирования и реализации механизма правоотношений.

Ученые - представители старых школ юриспруденции утверждали, что «произвести нравственную оценку права нельзя, иначе как возвысившись к тем основаниям, на которых покоится право, к тем началам, которые должны руководить законодателем в его деятельности» ${ }^{26}$. Петр Павлович Серков призывает выводить из тени «содержательные идейные ценности правовых норм». Следует принять позицию автора и в том, что обобщающая доктрина может сложиться лишь в результате системного собирания «высказанной исследователями конкретики научных представлений о правовой действительности». Именно с высоты таких теоретических конструкций и следует относиться к вопросу о рассмотрении механизма правоотношений, когда в перспективе «нравственное на-

${ }^{26}$ Новгородиев П. И. Указ. соч. С. 10. 


\section{Вестник ВГУ. Серия: Право}

чало межличностного общения» (с. 214) станет отражением постулатов идейной основы, позволяющей осуществлять с учетом нравственных обоснований и критериев правовое воздействие на субъектов общественных отношений.

Поиск итоговых оценочных суждений о монографии П. П. Серкова весьма затруднителен. Обычно указывается, что научный труд являет собою результативное, объемное, крупное, базисное исследование вопросов нравственности современного правового регулирования. На самом деле, это так и есть. Но мною высказанные слова - лишь повтор тривиальных суждений; в них отражаются обычные оценочные финальные формулировки исследовательского труда. Мне же более желательно подчеркнуть громадный вклад ученого в разработку концепции правового регулирования, построенного на учете потенциала нравственности и ее идейных постулатов и выраженного Петром Павловичем Серковым в многообразных системных взаимодействиях нравственности и правообразования, правовой культуры, правопонимания и правосознания, нравственной правовой социализации личности, полноценного учета ценностных параметров правовой регламентации. А для выяснения этих общих вопросов, ответы на которые даются в книге П. П. Серкова, придется вновь возвращаться к тексту монографии, вчитываться в непростые предложения и авторские умозаключения в поиске основного смысла теоретических конструкций, предлагаемого понимания и толкования терминов, установления правовой конкретики. Анализируемое издание уже стало крайне заметным фактом в отечественной правовой науке; думается, что и само монографическое содержание в будущем станет мощным стимулом для разрешения многочисленных проблем современной теории права и правовой государственности.

\section{Воронежский государственный уни- верситет}

Старилов Ю. Н., декан, заведующий кафбедрой административного и административного прочессуального права

336 юридического ббкультета, доктор юридических наук, профбессор, заслуженный деятель науки Российской Федерации

E-mail: juristar@vmail.ru
Voronezh State University

Starilov Yu. N., Dean, Head of the Administrative and Administrative Procedural Law Department of the Law Faculty, Doctor of Legal Sciences, Professor, Honoured Scientist of Russian Federation E-mail: juristar@vmail.ru 